\title{
Free fatty acids enhance breast cancer cell migration through plasminogen activator inhibitor-1 and SMAD4
}

\author{
Chang Hyun Byon ${ }^{1}$, Robert W Hardy ${ }^{2}$, Changchun Ren², Selvarangan Ponnazhagan², Danny R Welch ${ }^{1,2}$, \\ Jay M McDonald ${ }^{2,3}$ and Yabing Chen $^{2}$
}

\begin{abstract}
Obesity is a risk factor for breast cancer and is associated with increased plasma concentrations of free fatty acids (FFAs). We and others have demonstrated that FFA induces plasminogen activator inhibitor-1 (PAl-1) expression in a variety of cells. Emerging evidence supports elevation of PAl-1 as a prognostic marker for breast cancer. Therefore, we hypothesized that FFAs might increase expression of PAI-1 in breast cancer cells and facilitate breast cancer progression. Secreted PAI-1 was higher in invasive and metastatic MDA-MB-231 cells compared with less invasive and non-metastatic Hs578T cells. Utilizing FFAs with different saturation and chain lengths, we demonstrated that linoleic acid induced expression of PAI-1 in MDA-MB-231 cells. Linoleic acid also induced in vitro migration of MDA-MB-231. By contrast, other FFAs tested had little or no effect on PAI-1 expression or migration. Linoleic acid-induced breast cancer cell migration was completely inhibited by virally expressed antisense PAI-1 RNA. Furthermore, increased expression of PAI-1 by FFAs was not detected in the SMAD4-deficient MDA-MB-468 breast carcinoma cells. Electrophoretic mobility-shift assay confirmed that linoleic acid-induced expression of PAI-1 was mediated, at least in part, by SMAD4 in MDA-MB-231 cells. That linoleic acid induces PAI-1 expression in breast cancer cells through SMAD4 provides a novel insight into understanding the relationships between two migration-associated molecules, FFAs, and PAI-1.
\end{abstract}

Laboratory Investigation (2009) 89, 1221-1228; doi:10.1038/labinvest.2009.97; published online 14 September 2009

KEYWORDS: free fatty acids; breast cancer cell; migration; PAI-1; SMAD4

About 97 million adults in the United States are overweight or obese, which substantially increases the risk of cancer and morbidity. ${ }^{1}$ The predominant cancers associated with obesity include endometrial, breast, prostate, and colon. ${ }^{2-4}$ Among these cancers, breast cancer is the most frequently diagnosed cancer in woman. High levels of triglycerides in the blood and free fatty acids (FFAs) are linked with obesity. Increased plasma concentrations of FFAs are associated with breast cancer. ${ }^{5,6}$ Diverse effects of FFAs on breast cancer growth have been observed in cell culture and in epidemiological studies of mice xenograft models. ${ }^{7-9}$ However, the molecular mechanisms underlying the role of FFAs in breast cancer pathogenesis remain unknown.

Emerging clinical studies have implicated plasminogen activator inhibitor-1 (PAI-1) both in tumor tissues and in plasma as a key prognostic factor in breast cancer. PAI-1 is the primary inhibitor of urokinase-type (uPA) and tissuetype (tPA) plasminogen activators and belongs to the family of serine protease inhibitors. Recent studies showed that PAI-1 is dramatically upregulated in obesity, and increased FFAs concentrations in obesity are positively correlated with PAI-1 levels in plasma, ${ }^{10,11}$ suggesting that PAI- 1 may be important in mediating the effects of FFAs. PAI-1 is released into the circulation and extracellular spaces under physiological conditions by only a few cells: liver, smooth muscle, adipocytes, and platelets. However, under pathological conditions, tumor cells and endothelial cells secrete abundant PAI- $1 .{ }^{12}$

In cohort study, several components of the plasminogen activator system ( $\mathrm{uPA}$, the receptor uPAR (CD87), PAI-1, and PAI-2) are potential predictors of relapse-free survival and overall survival in 2780 patients with primary invasive breast cancer. ${ }^{13}$ In another study, PAI-1 level, which was determined in tumor tissue extracts by immunoenzymatic methods, was reported as a significant prognostic marker both in the primary breast cancer and for survival after long-term median follow-up of 77 months. ${ }^{14}$ Although initial studies focused

\footnotetext{
'Department of Cell Biology, University of Alabama at Birmingham, Birmingham, AL, USA; ${ }^{2}$ Department of Pathology, University of Alabama at Birmingham, Birmingham, AL, USA and ${ }^{3}$ Veterans Administration Medical Center, Birmingham, AL, USA

Correspondence: Dr Y Chen, PhD, Department of Pathology, University of Alabama at Birmingham, 1530 3rd Avenue South, 533 LHRB, Birmingham, AL 35294 , USA. E-mail: ybchen@uab.edu

Received 13 January 2009; revised 10 June 2009; accepted 11 June 2009
} 
on PAI-1 levels in tumor lysates and cytosols, tissue findings were then extended to plasma studies and similar results were seen. Specifically, research study showed increased levels of PAI- 1 above the normal cut-off in $24 \%$ of breast cancer plasmas, $30 \%$ of colon cancer plasmas, $40 \%$ of lung cancer plasmas, and $12 \%$ of prostate cancer plasmas. ${ }^{15}$ More recently, it was shown that metastatic breast cancer patients who had elevated pre-treatment plasma PAI-1 had a shorter overall survival than metastatic breast cancer patients with normal levels of PAI- $1 .{ }^{16}$ Moreover, a common polymorphism $(4 \mathrm{G} / 5 \mathrm{G})$ in the promoter region of the PAI-1 gene has been reported to influence transcription and plasma levels of PAI-1. Studies of different populations have shown consistently that subjects homozygous for the 4G allele have significantly higher plasma PAI-1 levels than those homozygous for the $5 \mathrm{G}$ allele. Patients homozygous for the $4 \mathrm{G}$ allele had significantly poorer disease-free survival and overall survival than those homozygous for the $5 \mathrm{G}$ allele, suggesting that implication of high plasma PAI-1 level in poor prognosis of breast cancer patients. ${ }^{17}$

We previously demonstrated that FFAs induced PAI-1 expression in human hepatoma HepG2 cells. $^{18,19}$ The data reported here represent the first effort to understand the link between elevation of FFAs and PAI-1 in the pathogenesis of breast cancer. PAI-1 expression is higher in invasive MDA-MB-231 cells compared with less invasive and nonmetastatic Hs578T cells. FFAs induced the expression of PAI-1 in breast cancer cells, which, in turn, contributes to increased migration. Further, FFA-induced PAI-1 expression was mediated by the transcription factor SMAD4. These studies provide insight into understanding the mechanism underlying FFAs and PAI-1 in regulation of breast cancer progression, and will facilitate exploring the application of drugs that are known to lower FFAs and PAI-1 for breast cancer therapy.

\section{MATERIALS AND METHODS Cell Culture}

The human breast cancer cell lines MDA-MB-231, Hs578T, and MDA-MB-468 were obtained from American Type Culture Collection (ATCC no. HTB-26, HTB-126, and HTB132 , respectively). MDA-MB-231 was cultured at $37^{\circ} \mathrm{C}$ with $5 \% \mathrm{CO}_{2}$ in Dulbecco's Modified Eagle's Medium (DMEM) supplemented with penicillin $(50 \mathrm{U} / \mathrm{ml})$, streptomycin $(50 \mu \mathrm{g} / \mathrm{ml})$, and $10 \%$ fetal bovine serum. Hs578T was maintained at $37^{\circ} \mathrm{C}$ with $10 \% \mathrm{CO}_{2}$ in DMEM supplemented with penicillin, streptomycin, insulin $(10 \mu \mathrm{g} / \mathrm{ml})$, and $10 \%$ fetal bovine serum. MDA-MB-468 was kept at $37^{\circ} \mathrm{C}$ with $5 \% \mathrm{CO}_{2}$ in RPMI 1640 supplemented with penicillin, streptomycin, insulin-transferrin-selenium (ITS; GIBCO-BRL, NY, USA), and $10 \%$ fetal bovine serum. Experiments were performed in Dulbecco's Modified Eagles media with Hams' nutrient mixture F12 (DME/F-12).

\section{FFA Preparation and Treatment}

FFA preparation and treatment of cells was performed as described previously by us. ${ }^{20}$ One percent fatty acid-free bovine serum albumin (FAF-BSA, fraction V; Sigma) was used as a vehicle for the FFA treatment. Sodium salts of FFAs (Sigma) were dissolved in water at certain temperatures (eg, linoleic acid at $55^{\circ} \mathrm{C}$ and stearic acid at $80^{\circ} \mathrm{C}$ ) and then added dropwise to $1 \%$ FAF-BSA in DME/F12. After adjusting to $\mathrm{pH} 7.4$ and filtering through a $0.22-\mu \mathrm{m}$ filter, all FFAs were verified using Wako NEFA C kits (Biochemical Diagnostics). For FFA treatment, $80 \%$ confluent cells were serum-starved and subsequently exposed to control condition or BSAbound FFAs.

\section{Western Blot Analysis}

Cells were seeded in six-well dishes at $1.5 \times 10^{5}$ cells/well and incubated for $24 \mathrm{~h}$. After a 24 -h period of serum starvation in medium containing $1 \%$ BSA, cells were incubated with or without BSA-bound fatty acid solution for $24 \mathrm{~h}$. After treatment, cells were washed and lysed in protein extraction buffer containing $20 \mathrm{mM}$ Tris (pH 7.5), $150 \mathrm{mM} \mathrm{NaCl}, 10 \%$ glycerol, $1 \%$ Triton X-100, $2 \mathrm{mM}$ EDTA, $1 \mathrm{mM}$ PMSF, and Complete Protease Inhibitor Cocktail (Roche, Mannheim, Germany). Lysates were cleared by centrifugation and protein concentrations of the supernatants were determined using the BCA protein assay (Pierce, IL, USA). Equal amounts of protein ( $20 \mu \mathrm{g}$ per lane) were separated by SDS-PAGE and transferred to PVDF membrane. Immunoblotting was performed according to the manufacturer's instructions using monoclonal anti-PAI-1 antibodies (IMA-33H1F7; Molecular Innovations Inc., MI, USA) and a chemiluminescence system (Amersham Biosciences, Uppsala, Sweden). Glyceraldehyde3-phosphate dehydrogenase (GAPDH) was used as a loading control. Protein band densities were determined by densitometric analysis.

\section{ELISA Analysis}

PAI-1 protein concentration in cell culture media was determined using the PAI-1 enzyme-linked immunosorbent assay (ELISA) kit (TintElize PAI-1; Biopool, Umeå, Sweden) according to the manufacturer's recommendations.

\section{RT-PCR Analysis}

Total RNA was isolated from breast cancer cells using Trizol (Invitrogen, CA, USA). RNA content and purity were determined by photometry at $260 v s 280 \mathrm{~nm}$. A $1 \mu$ g weight of total RNA was incubated with 20 pmol of oligo-dT primer for $2 \mathrm{~min}$ at $70^{\circ} \mathrm{C}$ and the mixture was subsequently cooled on ice for $5 \mathrm{~min}$. Reverse transcription was carried out using the Advantage RT-for-PCR kit (Clontech, CA, USA) for $1 \mathrm{~h}$ at $42^{\circ} \mathrm{C}$, with an additional $5 \mathrm{~min}$ at $94^{\circ} \mathrm{C}$ for inactivation of the reverse transcriptase. PCR was performed with the iCycler thermal cycler (Bio-Rad, CA, USA) using the Titanium Taq PCR kit (Clontech). The density of bands was 
analyzed with the use of densitometry and Kodak software (Eastman Kodak).

\section{Quantitative Reverse Transcriptase Real-Time PCR}

Relative quantification of PAI-1 mRNA was performed with the MyiQ Single-Color Real-Time PCR Detection System (Bio-Rad, CA, USA). The expression of PAI-1 and GAPDH mRNA was quantified by fluorescent SYBR green technology (Bio-Rad) as described previously. ${ }^{21}$ PCR were performed using specific primers for human PAI-1 (forward 5'-CAT CCCCCATCCTACGTGG and reverse 5'-CCCCATAGGGTGA GAAAACCA) and human GAPDH (forward 5'-ATGGGGAA GGTGAAGGTCG and reverse 5'-GGGGT CATTGATGGCA ACAATA). The mRNA level of PAI-1 was normalized by those of GAPDH used as an endogenous internal control. Thermal cycling conditions were $3 \mathrm{~min}$ at $94^{\circ} \mathrm{C}$ followed by 40 cycles of three-step PCR consisting of $15 \mathrm{~s}$ at $94^{\circ} \mathrm{C}, 15 \mathrm{~s}$ at $55^{\circ} \mathrm{C}$, and $15 \mathrm{~s}$ at $68^{\circ} \mathrm{C}$. All samples were amplified in triplicate.

\section{In Vitro Invasion Assay}

Matrigel matrix (Becton Dickinson Labware, NJ, USA) was polymerized in 24-well $6.5-\mathrm{mm}$ Transwell inserts containing polycarbonate membranes with $8-\mu \mathrm{m}$ pores to create invasion chambers as directed by the supplier. MDA-MB-231 cells and $\mathrm{Hs} 578 \mathrm{~T}$ cells were serum-starved for $24 \mathrm{~h}$, harvested by trypsinization after 24-h FFA treatment, and subsequently washed twice in DMEM without added serum or proteinase inhibitors. The cells were suspended in DME/F-12 at $3.5 \times 10^{5} / \mathrm{ml}$. Serum-free DME/F-12 $(0.6 \mathrm{ml})$ was added to each plate well and $0.1 \mathrm{ml}\left(3.5 \times 10^{4}\right.$ cells $)$ of the cell suspension was added to each insert. Assays were performed in triplicate wells for each condition. The plates of inserts were incubated for $8 \mathrm{~h}$ at $37^{\circ} \mathrm{C}$. After incubation, the chambers were processed and stained with Diff-Quick staining kit as directed by the supplier (IMEB Inc., CA, USA). Cells were counted in four fields per chamber under $\times 100$ magnification with the aid of a ruled grid.

\section{Generation of Breast Cancer Cells with PAI-1 Knockdown}

Adeno-associated virus (AAV) plasmid carrying antisense against PAI-1 mRNA was generated by subcloning cDNA encoding PAI-1 (provided by Dr Paul Declerck, University of Belgium) into pSub201 backbone. This plasmid carries a gene encoding green fluorescent protein (GFP) that has been used as a marker to monitor the cells after transfection. After confirmation by sequencing, the AAV-anti-PAI-1 plasmid was packaged into HEK 293 cells using pDG helper plasmid to produce recombinant AAV. ${ }^{22}$ MDA-MB-231 cells were then transduced with the AAV-anti-PAI-1 viruses or the control viruses, AAV-GFP. Transduced cells were sorted by their GFP expression with the use of flow cytometry and a stable clone with PAI-1 gene knocked down was identified by western blot analysis.

\section{Electrophoretic Mobility-Shift Assay}

Electrophoretic mobility-shift assay (EMSA) was performed by using $5 \mu \mathrm{g}$ of nuclear extracts prepared from untreated cells or cells treated with linoleic acid for $24 \mathrm{~h}$ and a probe (5'-TCGAGAGCCAGACAAAAAGCCAGACA TTTAGCCAG ACAC- $\left.3^{\prime}\right)$, which contains the consensus SMAD-binding sites that are underlined. ${ }^{23}$ The oligonucleotide was radioactively end-labeled with $\left[\gamma^{-}{ }^{32} \mathrm{P}\right]$ ATP and T4 polynucleotide kinase (New England Biolabs). Binding reactions were allowed to proceed at room temperature for $20 \mathrm{~min}$. ProteinDNA complexes were resolved by electrophoresis on nondenaturing $5 \%$ polyacrylamide gels and were visualized by autoradiography. The specificity of binding interactions was assessed by competition with a 200 molar excess of unlabeled double-stranded oligonucleotide of identical sequence. For supershift analysis of SMAD4, $2 \mu \mathrm{g}$ of SMAD4 (C-20-X) antibody from Santa Cruz Biotechnology Inc. was used.

\section{Statistical Analysis}

Data are presented as means \pm s.d. Differences in data between the groups were compared with Student's paired twotailed $t$-test or one-way ANOVA where appropriate. A $P$-value less than 0.05 was considered statistically significant.

\section{RESULTS}

\section{FFAs Increase the Expression of PAI-1 in Breast Cancer Cells}

The level of PAI-1 as a prognostic marker in primary breast cancer has been well documented. ${ }^{13-16}$ To determine whether the expression of PAI-1 may contribute to the invasiveness of breast cancer cells, we measured the secreted levels of PAI-1 in two breast cancer cell lines, Hs578T and MDA-MB-231. As determined by ELISA, the secreted levels of PAI- 1 were higher in the highly metastatic MDA-MB-231 cells as compared with that in the less invasive Hs578T cells (fold $=5.7 \pm 0.8$ for MDA-MB-231 vs Hs578T, $n=4, P=0.002$; Figure 1).

The effect of FFAs on the expression of PAI-1 in MDAMB-231 cells was determined using FFAs with different saturation and chain lengths (Figure 2). We found that linoleic acid and oleic acid (to a lesser extent) induced the expression of intracellular PAI-1 protein in MDA-MB-231, whereas other FFAs had no effect on the expression of PAI-1. Treatment with linoleic acid for $24 \mathrm{~h}$ resulted in the greatest induction of intracellular PAI-1 in MDA-MB-231 cells (fold $=1.8 \pm 0.2$ for linoleic acid compared with control, $n=4, P=0.004$; Figure 2a). Secretion levels of PAI-1 were determined in MDA-MB-231 cells treated with FFAs for $24 \mathrm{~h}$ by ELISA assay. Linoleic acid induced the expression of secreted PAI-1, whereas other FFAs showed no effect on the secretion of PAI-1 (fold $=2.2 \pm 0.3$ for linoleic acid compared with control, $n=3, P=0.0016$; Figure $2 \mathrm{~b}$ ). We further determined that PAI-1 mRNA was increased in MDA-MB231 cells after exposure to linoleic acid and oleic acid for $24 \mathrm{~h}$ as determined by RT-PCR (fold $=1.4 \pm 0.3$ for linoleic acid, $n=3, P<0.01$; Figure $2 \mathrm{c}$ ). The induction of PAI- 1 mRNA by 
linoleic acid was confirmed by quantitative reverse transcriptase real-time PCR (fold $=1.5 \pm 0.5$ compared with control, $n=3, P=0.01$; Figure 2d).

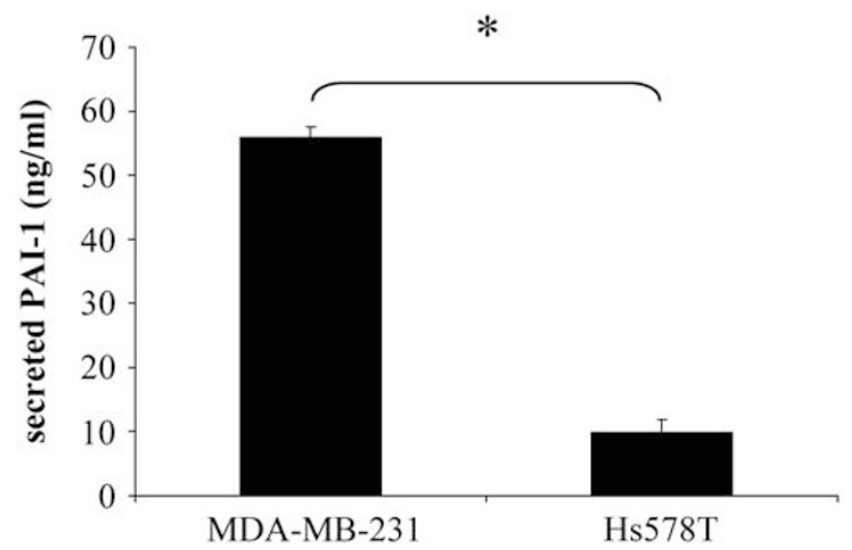

Figure 1 Secreted PAI-1 levels in MDA-MB-231 and Hs578T cells. Cells were seeded in six-well dishes at $1.5 \times 10^{5}$ cells/well and incubated for $24 \mathrm{~h}$. After a $24-\mathrm{h}$ period of serum starvation in medium containing $1 \%$ BSA, cells at $90 \%$ confluency were incubated with or without BSA-bound fatty acid solution for $24 \mathrm{~h}$. Secreted PAl-1 expression levels in the media of MDA-MB231 and Hs578T cells after 24-h serum starvation were analyzed by ELISA assay. ELISA results represent the means \pm s.d. of four independent experiments; ${ }^{\star} n=4, P=0.002$ by Student's $t$-test.
FFA-Induced In Vitro Migration of MDA-MB-231 Cells

Differential effects of FFAs on breast cancer cell growth and invasion have been demonstrated in previous reports. ${ }^{24,25} \mathrm{To}$ investigate the effect of FFAs on the migration of MDA-MB231 cells and Hs578T cells, an in vitro invasion assay using Matrigel-coated filters was performed. Results showed that linoleic acid induced the migration of MDA-MB-231 cells (fold $=4.0 \pm 1.1$ compared with control, $n=3$, $P<0.001)$. Oleic acid showed less effect on cell migration (fold $=1.9 \pm 0.1$ compared with control, $n=3, P<0.01$ ) and other FFAs had no effect (Figure 3a). While, Hs578T cells showed no significant increase in migration by all FFAs treated, indicating that induced PAI-1 expression by FFAs might be required for breast cancer cell migration in vitro (Figure 3b).

\section{Inhibition of PAI-1 by Antisense mRNA Blocked FFA-Induced Migration of MDA-MB-231 Cells}

The specificity of and requirement for PAI-1 in mediating FFA-regulated breast cancer cell migration was characterized with a MDA-MB-231 derivative in which PAI-1 expression was knocked down by AAV carrying anti-PAI- $1 .{ }^{22}$ Immunoblotting analysis was performed to verify reduced expression of PAI-1 following AAV-anti-PAI-1 viral
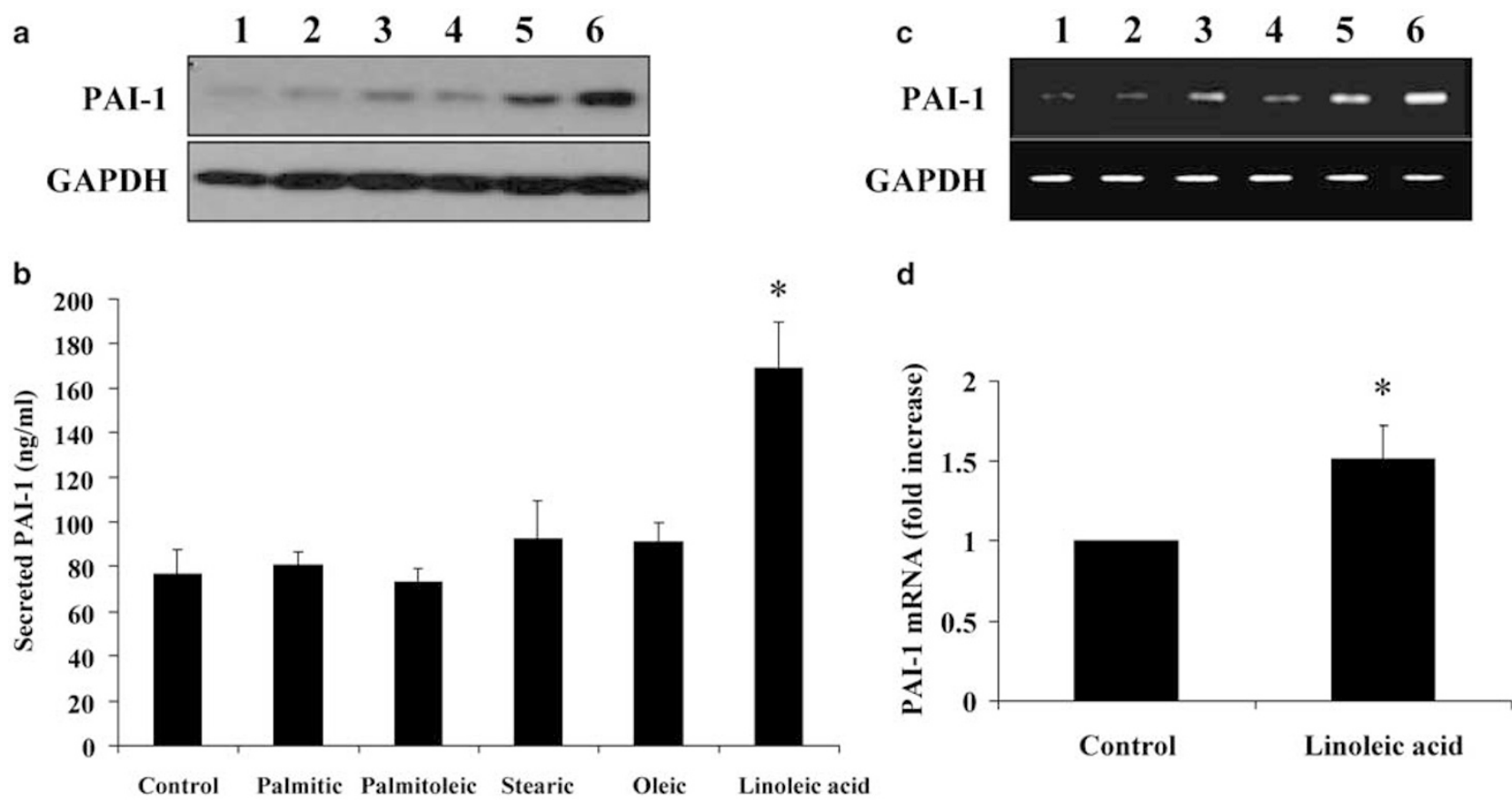

Figure 2 FFAs increased the expression of PAl- 1 in breast cancer cells. Cells were seeded in six-well dishes at $1.5 \times 10^{5}$ cells/well and incubated for $24 \mathrm{~h}$. After a 24-h period of serum starvation in medium containing $1 \%$ BSA, cells at $90 \%$ confluency were incubated with or without BSA-bound fatty acid solution for $24 \mathrm{~h}$. (a) Intracellular PAl-1 expression levels in cell lysates of MDA-MB-231 after 24-h exposure to $500 \mu \mathrm{M}$ FFAs was analyzed by western blot. (lane 1: control; lane 2: palmitic acid; lane 3: palmitoleic acid; lane 4: stearic acid; lane 5: oleic acid; lane 6: linoleic acid). (b) Secreted PAI-1 expression levels in the media of MDA-MB-231 after 24-h exposure to $500 \mu \mathrm{M}$ FFAs were determined by ELISA assay. Results represent the means \pm s.d. of three independent experiments; ${ }^{\star} n=3, P=0.002$ by ANOVA. (c) PAI- 1 mRNA expression levels in MDA-MB-231 after 24-h exposure to $500 \mu \mathrm{M}$ FFAs were analyzed by RT-PCR (lane 1: control; lane 2: palmitic acid; lane 3: palmitoleic acid; lane 4: stearic acid; lane 5: oleic acid; lane 6: linoleic acid). (d) PAI-1 mRNA expression levels in MDA-MB-231 after 24-h exposure to $500 \mu \mathrm{M}$ linoleic acid was analyzed by quantitative reverse transcriptase real-time PCR. Results represent the means \pm s.d. of three independent experiments; ${ }^{\star} n=3, P=0.01$ by Student's $t$-test. 

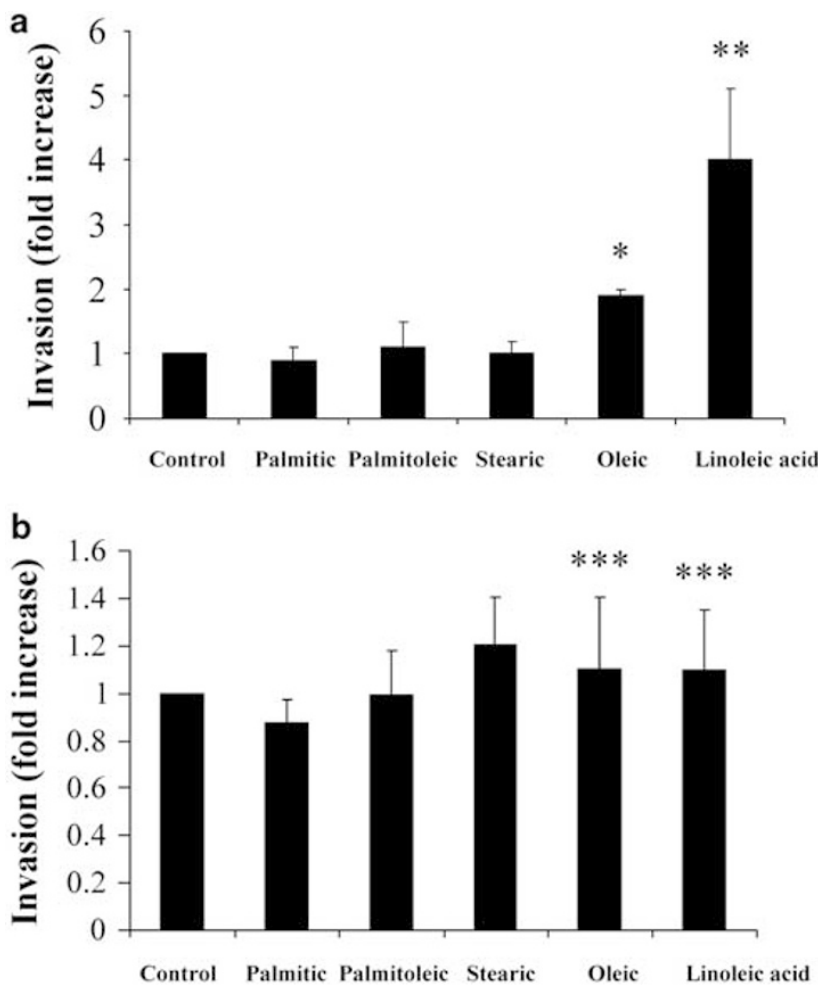

Figure 3 FFAs induced in vitro migration of MDA-MB-231. Matrigel matrix polymerized in 24-well $6.5-\mathrm{mm}$ Transwell inserts containing polycarbonate membranes with $8-\mu \mathrm{m}$ pores to create invasion chambers. Cells were serum-starved for $24 \mathrm{~h}$, harvested by trypsinization after 24-h FFA treatment and subsequently washed twice in DMEM without added serum or proteinase inhibitors. Cells were suspended in DME/F-12 at $3.5 \times 10^{5} / \mathrm{ml}$. Serum-free DME/F-12 $(0.6 \mathrm{ml})$ was added to each plate well and $0.1 \mathrm{ml}$ $\left(3.5 \times 10^{4}\right.$ cells) of the cell suspension was added to each insert. Induction of migration of MDA-MB-231 cells (a) and Hs578T cells (b) after 24-h exposure to $500 \mu \mathrm{M}$ FFAs was analyzed by in vitro Matrigel assay. Results represent the means \pm s.d. of three independent experiments; ${ }^{*} n=3$, $P<0.01,{ }^{* *} n=3, P<0.009$ and ${ }^{* *} n=3$, not significant by ANOVA.

transduction into MDA-MB-231. Linoleic acid-induced expression of PAI-1 protein in cells infected with AAV-antiPAI-1 viruses was decreased when compared with the cells infected with control viruses (Figure 4a).

Further, we determined whether expression of PAI-1 contributes to the effect of linoleic acid on the migration of breast cancer cells. Linoleic acid-induced migration was blocked in MDA-MB-231 cells transduced with AAV-antiPAI-1, indicating a critical role of PAI-1 in FFA-induced migration of MDA-MB-231 cells (Figure $4 \mathrm{~b}$ ).

\section{SMAD4 Mediated FFA-Induced Expression of PAI-1 in Breast Cancer Cells}

We previously identified an FFA-response element within the $5^{\prime}$ flanking region of the PAI-1 gene in HepG2 cells. Sequence analysis revealed that this region contains a SMAD4-binding element. ${ }^{20}$ To investigate the role of SMAD4 in FFA-induced PAI-1 expression in MDA-MB-231, we performed an EMSA. The SMAD-binding activity was markedly increased in linoleic acid-treated cells and it was inhibited when unlabeled SMAD4 oligonucleotide was added to the binding reaction (Figure 5a). Using an antibody specific for SMAD4, we were able to determine a higher-molecular-weight band, indicating the presence of SMAD4 in the binding complex. This result suggests that linoleic acid activates SMAD4 signaling in MDA-MB-231 cells that contribute to the increase in PAI-1 expression by linoleic acid.

Furthermore, we characterized the role of SMAD4 in FFAinduced expression of PAI-1 using SMAD4-deficient MDAMB-468 cells, which are breast carcinoma cells with a homozygous deletion for SMAD4. ${ }^{26}$ Unlike MDA-MB-231 cells, we found that the increased expression of PAI-1 by any FFA was not detected in the SMAD4-deficient cells, which confirmed that FFAs induce the expression of PAI-1 through SMAD4 signaling in breast cancer cells (Figure 5b).

\section{DISCUSSION}

Increased PAI-1 and FFAs are both associated with poor prognosis of breast cancer. We hypothesized that there was a link between the elevation of FFAs and PAI-1 levels, which contributes to breast cancer pathogenesis. It has been postulated that higher consumption of n-6 PUFA, particularly linoleic acid, in the diet may contribute to the high breast cancer incidence in Western women. ${ }^{27}$ Although both FFA and PAI-1 levels are generally elevated in breast cancer patients, there is no clinical link between plasma FFAs and PAI-1 levels in breast cancer patients. Our results demonstrate that PAI-1 level is increased by FFAs, especially linoleic acid, in breast cancer cells in vitro, thus establishing a connection between increased FFA levels and PAI-1 in breast cancer cells.

To begin addressing this hypothesis, we investigated the effect of five of the most abundant FFAs in plasma on the expression of PAI-1 and breast cancer cell migration. As shown previously, ${ }^{28}$ linoleic acid had the greatest effect on the induction of PAI-1 in MDA-MB-231 cells, consistent with our previous observations that linoleic acid increased the expression of PAI-1 in HepG2 cells. ${ }^{18,19}$ It was also reported that butyric acid inhibited both cell proliferation and uPA activity, but had no effect on PAI-1 level in MDA-MB-231 cells, ${ }^{29}$ again suggesting that FFAs with different saturation and chain lengths show different effects on the expression of PAI-1. A concentration of $500 \mu \mathrm{M}$ was selected for individual FFAs because our previous studies demonstrated that this concentration of FFAs induces PAI-1 expression in HepG2 cells. ${ }^{18,19}$ In addition, total serum FFA concentrations of at least $5 \mathrm{mM}$ have been reported in humans ${ }^{30}$ which makes $500 \mu \mathrm{M}$ a physiologically attainable concentration, if not normal. ${ }^{31}$

Previously, we have reported that FFAs induce PAI-1 expression in HepG2 cells by activating a transcription factor that binds with the sequence $5^{\prime}-\mathrm{TG}(\mathrm{G} / \mathrm{C}) 1-2 \mathrm{CTG}-3^{\prime}$, which is repeated four times in the PAI-1 promoter $(-528$ and $-599) .^{20}$ One of the SMAD3/SMAD4-binding sequences 


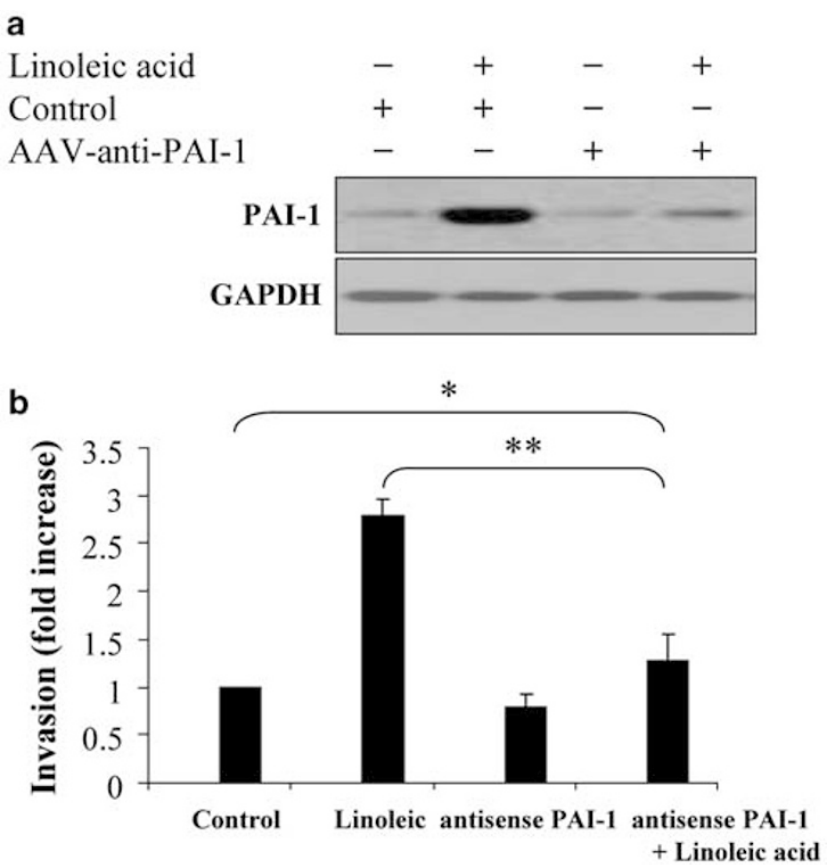

Figure 4 Inhibition of PAl-1 by antisense blocked FFA-induced migration of MDA-MB-231. (a) MDA-MB-231 cells transduced with control AAV-GFP or AAV-anti-PAl-1 virus were treated with $500 \mu \mathrm{M}$ linoleic acid for $24 \mathrm{~h}$. Intracellular expression of PAl-1 was analyzed by western blot. (b) In vitro Matrigel assay following AAV-anti-PAI-1 viral transduction into MDA-MB231. Results represent the means \pm s.d. of three independent experiments; ${ }^{\star} n=3$, not significant and ${ }^{\star *} n=3, P=0.0013$ by ANOVA.

termed CAGA boxes, which are essential and sufficient for the induction of PAI- 1 by TGF- $\beta 1,{ }^{23}$ has been identified in the PAI-1 promoter -580 within the FFA-responsive region. We showed by EMSA that SMAD4 is activated by treatment with linoleic acid of MDA-MB-231 cells (Figure 5a). Moreover, we found that linoleic acid failed to increase the expression of PAI-1 in SMAD4-deficient MDA-MB-468 cells (Figure 5b), suggesting that SMAD4 mediates linoleic acidinduced PAI-1 expression in breast cancer cells.

PAI-1 can potentially influence cell motility at several levels by competing with uPAR and integrins to bind vitronectin and/or by inducing the internalization of adhesion receptors. ${ }^{32}$ TGF- $\beta 1$-induced PAI- 1 has been reported to be associated with its stimulatory effect on invasion and metastasis of MDA-MB-231 cells. ${ }^{29}$ Incubation of endothelial cells with conditioned medium from two breast cancer cell lines (MCF7 and MDA-MB-231) also demonstrated that conditioned medium from highly invasive MDA-MB-231 cells increased the tube formation of endothelial cells, which was related to the high levels of uPA and PAI- 1 secreted by MDA-MB-231 cells as compared with low levels in MCF7 cells. ${ }^{33}$ Furthermore, downregulation of the expression of the PAI-1 gene in MDA-MB-231 cells was associated with inhibition of invasion, indicating that the expression of PAI-1 may be associated with the invasion of MDA-MB-231 cells. ${ }^{34}$ Therefore, our results, demonstrating that the highly invasive a

\begin{tabular}{|c|c|c|c|c|c|c|}
\hline Linoleic acid & - & - & - & + & + & - \\
\hline Hot probe & + & + & + & + & + & + \\
\hline Cold competitor & - & - & + & - & + & - \\
\hline$\alpha-\mathrm{SMAD} 4$ & - & - & - & - & - & + \\
\hline
\end{tabular}

Supershift

4 SMAD4
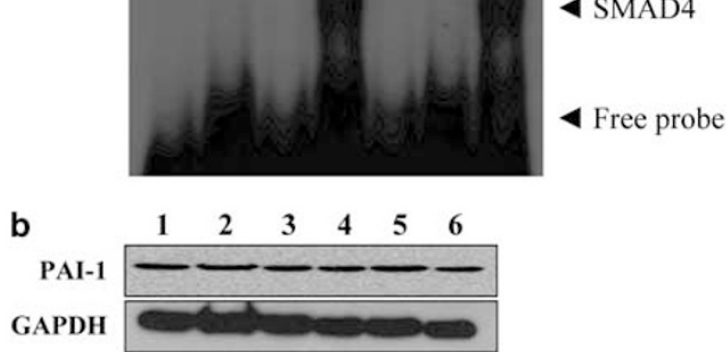

Figure 5 SMAD4 mediated FFA-induced expression of PAl-1in breast cancer cells. (a) Increased binding of SMAD4 in nuclear extracts of MDA-MB231 treated with $500 \mu \mathrm{M}$ linoleic acid for $24 \mathrm{~h}$ was identified by EMSA. (b) Intracellular PAl-1 expression levels in cell lysates of MDA-MB-468 after 24-h exposure to $500 \mu \mathrm{M}$ FFAs were analyzed by western blot. Results indicate the representative image of three independent experiments (lane 1: control; lane 2: palmitic acid; lane 3: palmitoleic acid; lane 4: stearic acid; lane 5: oleic acid; lane 6: linoleic acid).

MDA-MB-231 cells expressed greater amounts of secreted PAI-1 compared with less invasive Hs578T cells (Figure 1), are consistent with these previous observations that secreted PAI-1 might contribute to the invasion and metastasis of breast cancer. The effect of PAI-1 induced by FFAs on breast cancer cell migration was further investigated. The induction of PAI-1 by linoleic acid in MDA-MB-231 cells paralleled the linoleic acid-induced increase in cell migration (Figure 3a), suggesting that PAI-1 induced by linoleic acid in MDA-MB231 might be responsible for inducing migration of the cancer cells in vitro. By inhibiting PAI-1 expression in MDAMB-231 cells, we demonstrated that PAI-1 expression is necessary for linoleic acid-induced MDA-MB-231 breast cancer cell migration (Figure 4b). Moreover, less invasive Hs578T cells (Figure $3 \mathrm{~b}$ ) and SMAD4-deficient MDA-MB-468 cells (data not shown) showed no significant increase in migration, indicating the importance of SMAD4-mediated PAI-1 expression by linoleic acid on breast cancer cell migration.

A previous dietary study also demonstrated that a linoleic acid-enriched diet (12\% compared with $2 \%$ normal) increases the incidence of microscopic metastases in MDA-MB231 cell tumor-bearing nude mice ( $68 v s$ 42\%). While linoleic acid did not affect the pro-migratory and pro-invasive factors, type IV collagenase and gelatinase in MDA-MB-231 cells, ${ }^{35}$ it has been shown to stimulate MDA-MB-231 cell growth $^{36}$ and to increase MDA-MB-435 breast cancer cell invasion in vitro in a cyclooxygenase-dependent manner. ${ }^{37}$ 
Also, a direct correlation was demonstrated between COX-2 and PAI-1 immunohistochemical expression in a series of breast cancer cases, ${ }^{38}$ suggesting a putative link between expression of PAI-1 and linoleic acid-induced COX-2 signaling.

In summary, linoleic acid stimulates PAI-1 expression and increases the invasion of MDA-MB-231 breast cancer cells through the SMAD4 signaling pathway. As mentioned above, the effect of FFAs, particularly linoleic acid, on the growth and invasion of human breast cancer cells was examined in terms of eicosanoid synthesis catalyzed by cyclooxygenase and lipooxygenase. ${ }^{37}$ For the first time, we identified the importance of transcriptional activation of PAI-1 mediated by FFA-SMAD4 signaling in human breast cancer cell invasion in vitro. It was previously shown that PAI-1 deficiency in mice retarded fibrosarcoma development. ${ }^{39}$ It will be also interesting to investigate the effect of linoleic acid-enriched diet on implanted human breast cancer cell growth and invasion in PAI-1-deficient mice. Our study suggests that PAI-1 could be a target for treatment for breast cancer by novel dietary and/or pharmaceutical strategies to inhibit tumor invasion and metastasis.

\section{ACKNOWLEDGEMENT}

We thank Marsha Moore and Department of Pathology of the University of Alabama at Birmingham for administrative and financial support of the work.

\section{DISCLOSURE/CONFLICT OF INTEREST}

The authors declare no conflict of interest.

1. Pi-Sunyer FX, Becker DM, Bouchard C, et al. Executive summary of the Clinical Guidelines on the Identification, Evaluation, and Treatment of Overweight and Obesity in Adults. Arch Intern Med 1998;158:18551867.

2. Abu-Abid S, Szold A, Klausner J. Obesity and cancer. J Med 2002;33: 73-86.

3. Bergstrom A, Pisani $P$, Tenet $V$, et al. Overweight as an avoidable cause of cancer in Europe. Int J Cancer 2001;91:421-430.

4. Simopoulos AP. Energy imbalance and cancer of the breast, colon and prostate. Med Oncol Tumor Pharmacother 1990;7:109-120.

5. Loskutoff DJ, Samad F. The adipocyte and hemostatic balance in obesity: studies of PAl-1. Arterioscler Thromb Vasc Biol 1998;18:1-6.

6. Bani IA, Williams CM, Boulter PS, et al. Plasma lipids and prolactin in patients with breast cancer. Br J Cancer 1986;54:439-446.

7. Senzaki H, Iwamoto S, Ogura $E$, et al. Dietary effects of fatty acids on growth and metastasis of KPL-1 human breast cancer cells in vivo and in vitro. Anticancer Res 1998;18:1621-1627.

8. Hardy S, Langelier Y, Prentki M. Oleate activates phosphatidylinositol 3-kinase and promotes proliferation and reduces apoptosis of MDA-MB-231 breast cancer cells, whereas palmitate has opposite effects. Cancer Res 2000;60:6353-6358.

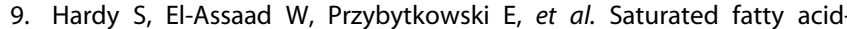
induced apoptosis in MDA-MB-231 breast cancer cells. A role for cardiolipin. J Biol Chem 2003:278:31861-31870.

10. Alessi MC, Bastelica $D$, Morange $P$, et al. Plasminogen activator inhibitor 1, transforming growth factor-beta1, and BMI are closely associated in human adipose tissue during morbid obesity. Diabetes 2000:49:1374-1380

11. Bastard JP, Bruckert E, Robert JJ, et al. Are free fatty acids related to plasma plasminogen activator inhibitor 1 in android obesity? Int J Obes Relat Metab Disord 1995;19:836-838.

12. Binder BR, Christ G, Gruber F, et al. Plasminogen activator inhibitor 1 : physiological and pathophysiological roles. News Physiol Sci 2002;17:56-61.
13. Foekens JA, Peters HA, Look MP, et al. The urokinase system of plasminogen activation and prognosis in 2780 breast cancer patients. Cancer Res 2000;60:636-643.

14. Harbeck N, Thomssen C, Berger U, et al. Invasion marker PAl-1 remains a strong prognostic factor after long-term follow-up both for primary breast cancer and following first relapse. Breast Cancer Res Treat 1999;54:147-157.

15. Hamer PJ, Morris LD, Jarosz DE, et al. PAI-1 and uPA:PAI-1 complex levels in normal plasma and elevations in cancer plasma [abstract]. In: Kolodner RD (ed.), Proceedings of the 93rd Annual Meeting of the American Association for Cancer Research, 2002, Abstract no. 4496

16. Hamer PJ, Goshgarian N, Smith J. Plasma PAI-1 and UPA:PAI-1 complex levels a predictive and prognostic factors in patients with metastatic breast cancer [abstract]. In: Courtneidge SA (ed.), Proceedings of the 94th Annual Meeting of the American Association for Cancer Research, 2003, Abstract no. 6356.

17. Zhang $X$, Shu $X O, C a i$, et al. Functional plasminogen activator inhibitor-1 gene variants and breast cancer survival. Clin Cancer Res 2006;12:6037-6042.

18. Chen Y, Sobel BE, Schneider DJ. Effect of fatty acid chain length and thioesterification on the augmentation of expression of plasminogen activator inhibitor-1. Nutr Metab Cardiovasc Dis 2002;12:325-330.

19. Chen Y, Schneider DJ. The independence of signaling pathways mediating increased expression of plasminogen activator inhibitor type 1 in HepG2 cells exposed to free fatty acids or triglycerides. Int J Exp Diabetes Res 2002;3:109-118.

20. Chen Y, Billadello JJ, Schneider DJ. Identification and localization of a fatty acid response region in the human plasminogen activator inhibitor-1 gene. Arterioscler Thromb Vasc Biol 2000;20: 2696-2701.

21. Castello R, Estelles A, Vazquez C, et al. Quantitative real-time reverse transcription-PCR assay for urokinase plasminogen activator, plasminogen activator inhibitor type 1 , and tissue metalloproteinase inhibitor type 1 gene expressions in primary breast cancer. Clin Chem 2002;48:1288-1295.

22. Ponnazhagan S, Mahendra G, Kumar S, et al. Adeno-associated virus 2 mediated antiangiogenic cancer gene therapy: long-term efficacy of a vector encoding angiostatin and endostatin over vectors encoding a single factor. Cancer Res 2004;64:1781-1787.

23. Liu L, Santora R, Rao JN, et al. Activation of TGF-beta-Smad signaling pathway following polyamine depletion in intestinal epithelial cells. Am J Physiol Gastrointest Liver Physiol 2003;285:G1056-G1067.

24. Hilakivi-Clarke $L$, Onojafe I, Raygada $M$, et al. Breast cancer risk in rats fed a diet high in $n-6$ polyunsaturated fatty acids during pregnancy. J Natl Cancer Inst 1996;88:1821-1827.

25. Chajès $V$, Sattler $W$, Stranzl $A$, et al. Influence of $n-3$ fatty acids on the growth of human breast cancer cells in vitro: relationship to peroxides and vitamin-E. Breast Cancer Res Treat 1995;34:199-212.

26. Ramachandra M, Atencio I, Rahman A, et al. Restoration of transforming growth factor beta signaling by functional expression of smad4 induces anoikis. Cancer Res 2002;62:6045-6051.

27. Stoll BA. Breast cancer and the western diet: role of fatty acids and antioxidant vitamins. Eur J Cancer 1998;34:1852-1856.

28. Byon $\mathrm{CH}$, Hardy RW, Welch DR, et al. Augmentation of plasminogen activator inhibitor-1 by free fatty acids in breast cancer cells [abstract]. In: Haber DA (ed.), Proceedings of the 97th Annual Meeting of the American Association for Cancer Research, 2006, Abstract no. 4374

29. Dong-Le Bourhis $X$, Lambrecht V, Boilly B. Transforming growth factor beta 1 and sodium butyrate differentially modulate urokinase plasminogen activator and plasminogen activator inhibitor-1 in human breast normal and cancer cells. Br J Cancer 1998;77:396-403.

30. Malchoff CD, Pohl SL, Kaiser DL, et al. Determinants of glucose and ketoacid concentrations in acutely hyperglycemic diabetic patients. Am J Med 1984;77:275-285.

31. Wirth A, Neermann G, Eckert W, et al. Metabolic response to heavy physical exercise before and after a 3-month training period. Eur J Appl Physiol Occup Physiol 1979;41:51-59.

32. Dellas C, Loskutoff DJ. Historical analysis of PAl-1 from its discovery to its potential role in cell motility and disease. Thromb Haemost 2005;93:631-640. 
33. Bajou K, Lewalle JM, Martinez CR, et al. Human breast adenocarcinoma cell lines promote angiogenesis by providing cells with UPA-PAl-1 and by enhancing their expression. Int J Cancer 2002;100: 501-506.

34. Siri S, Chen MJ, Chen TT. Inhibition of human breast cancer cell (MBA-MD-231) invasion by the Ea4-peptide of rainbow trout pro-IGF-I. J Cell Biochem 2006;99:1363-1373.

35. Rose DP, Connolly JM, Liu XH. Effects of linoleic acid on the growth and metastasis of two human breast cancer cell lines in nude mice and the invasive capacity of these cell lines in vitro. Cancer Res 1994;54:6557-6562.

36. Earashi M, Noguchi M, Kinoshita K, et al. Effects of eicosanoid synthesis inhibitors on the in vitro growth and prostaglandin $E$ and leukotriene $B$ secretion of a human breast cancer cell line. Oncology 1995;52: $150-155$.

37. Liu XH, Connolly JM, Rose DP. Eicosanoids as mediators of linoleic acid-stimulated invasion and type IV collagenase production by a metastatic human breast cancer cell line. Clin Exp Metastasis 1996;14:145-152.

38. Minisini AM, Fabbro D, Di Loreto $C$, et al. Markers of the uPA system and common prognostic factors in breast cancer. Am J Clin Pathol 2007;128:112-117.

39. Gutierrez LS, Schulman A, Brito-Robinson T, et al. Tumor development is retarded in mice lacking the gene for urokinase-type plasminogen activator or its inhibitor, plasminogen activator inhibitor-1. Cancer Res 2000;60:5839-5847. 